ORIGINAL ARTICLE / ARTIGO ORIGINAL

\title{
Association between area-level education and the co-occurrence of behavior-related risk factors: a multilevel analysis
}

\author{
Associação entre educação da vizinhança e a coocorrência \\ de fatores de risco comportamentais: uma análise multinivel
}

Antonio Fernando Boing ${ }^{\prime, \prime \prime}$ (D), SV Subramanian' (D), Alexandra Crispim Boing,,"l (D)

\begin{abstract}
Introduction: This study aimed to investigate the association of four different risk factors for chronic diseases and accumulation of these health behaviors with area-level education, regardless of individuallevel characteristics in Brazil. Methods: A population-based cross-sectional study was carried out in Southern Brazil including 1,720 adults in $2009 / 2010$. The simultaneous occurrence of tobacco smoking, abusive drinking, unhealthy eating habits, and physical inactivity was investigated. Using multilevel models, we tested whether area-level education was associated with each risk factor and with the co-occurrence of them after controlling sociodemographic individual-level variables. Results: We observed a between-group variance of 7.79, 7.11, 6.84 and $1.08 \%$ for physical inactivity, problematic use of alcohol, unhealthy eating habits, and smoking, respectively. The between-group variance for the combination of four behaviors was $14.2 \%$. Area-level education explained a significant proportion of the variance observed in physical inactivity and unhealthy eating habits. Residents of low educational level neighborhoods showed a 2.40 (95\%CI 1.58 - 3.66) times higher chance of unhealthy eating and $1.78(95 \% \mathrm{CI} 1.19-2.67)$ times higher chance of physical inactivity. The likelihood of individuals with two or three/four risk factors was simultaneously higher among residents of low educational level neighborhoods. Conclusion: Public policies should consider the area-level characteristics, including education to control risk factors for chronic diseases.
\end{abstract}

Keywords: Chronic disease. Risk factors. Education. Socioeconomic factors. Multilevel analysis.

'Department of Society, Human Development and Health, T.H. Chan Harvard School of Public Health - Boston, United States.

"Post-Graduate Program in Public Health, Universidade Federal de Santa Catarina - Florianópolis (SC), Brazil.

Corresponding author: Antonio Fernando Boing. Department of Public Health, Universidade Federal de Santa Catarina. Campus Universitário Trindade, CEP: 88040-900, Florianópolis, SC, Brazil. E-mail: antonio.boing@ufsc.br

Conflict of interests: nothing to declare - Financial support: Antonio Fernando Boing received a post-doctorate scholarship from Coordenação de Aperfeiçoamento de Pessoal de Nível Superior - CAPES (3111-13-0) and grants for research productivity (Conselho Nacional de Desenvolvimento Científico e Tecnológico - CNPq). 
RESUMO: Introdução: O objetivo do presente estudo foi investigar a associação de quatro diferentes fatores de risco para doenças crônicas e seu acúmulo com o nível educacional da vizinhança de moradia, controlando-se por características individuais. Métodos: Um estudo transversal de base populacional foi realizado no sul do Brasil com 1.720 adultos, em 2009/2010. A ocorrência simultânea de tabagismo, uso abusivo de álcool, hábitos alimentares não saudáveis e inatividade física foi investigada. Modelos multiníveis testaram se a educação da vizinhança estava associada com cada fator de risco e com a co-ocorrência deles, ajustando-se por variáveis individuais. Resultados: Houve variância entregrupos (VPC) de 7,79, 7,11, 6,84 e 1,08\% para inatividade física, uso problemático de álcool, hábitos alimentares não saudáveis e tabagismo, respectivamente. O VPC para a combinação dos quatro comportamentos foi de $14,2 \%$. A educação da vizinhança explicou significativa proporção da variância da inatividade física e dos hábitos alimentares não saudáveis. Residentes de vizinhanças que tinham baixo nível educacional mostraram 2,40 (IC95\% 1.58 - 3.66) vezes mais chance de hábitos alimentares não saudáveis e 1,78 (IC95\% 1.19 - 2.67) vez mais chance de inatividade física. A probabilidade de indivíduos terem dois ou mais fatores de risco simultâneos foi maior entre residentes de vizinhanças com nível educacional mais baixo. Conclusão: Políticas públicas devem considerar características da vizinhança, incluindo a educação, quando tiverem como objetivo controlar os fatores de risco para doenças crônicas.

Palavras-chave: Doença crônica. Fatores de risco. Educação. Fatores socioeconômicos. Análise multinível.

\section{INTRODUCTION}

Tobacco smoking, alcohol consumption, unhealthy eating habits, and physical inactivity account for an expressive proportion of chronic diseases, such as cancer, stroke, and ischemic heart disease ${ }^{1}$. Individual factors associated with these risk behaviors have been widely reported. Demographic and socioeconomic characteristics have been described as important determinants of exposure to such behaviors, and there is, in general, greater prevalence of risk factors in men, individuals of low socioeconomic level, and less educated groups $\mathrm{s}^{1-4}$.

In addition to individual factors, multilevel studies have shown that the neighborhood in which people live also influences their health status and behaviors, including exposure to risk factors of chronic diseases ${ }^{5.8}$. Different contextual factors may impact on individual health. Macintyre $\&$ Ellaway ${ }^{9}$ cite the availability of healthy environments at home, work, and play (i.e. good housing, healthy food availability), physical features of the environment shared by all residents (i.e. safe streets, green places, air and water quality), services provided to support people in their daily lives (i.e. lighting, education, street cleaning), and sociocultural features of the locality. Together, these physical and environmental characteristics may increase or decrease unfavorable health outcomes. However, most of these multilevel studies have been carried out in developed countries and have analyzed each risk factor independently. Few studies have analyzed the simultaneous exposure to more than one of these behaviors ${ }^{10}$ and considered the neighborhood context ${ }^{11}$, particularly in developing countries. 
In terms of public health policy, health promotion programs based on actions oriented to modify simultaneous behaviors are much more worthy, because this strategy has shown to be more effective than those based on isolated behaviors ${ }^{12}$. Furthermore, public health policies that consider contextual variables together with individual factors allow for a much more comprehensive approach ${ }^{13}$.

This study aimed to assess the association of four different risk factors for chronic diseases and the accumulation of these health behaviors with area-level education, regardless of individual-level characteristics in the Brazilian population.

\section{METHODS}

\section{STUDY POPULATION}

This is a population-based cross-sectional study nested in a cohort study of adults. People aged 20 to 59 years living in Florianópolis, Brazil, were interviewed in order to evaluate several health outcomes. This city is located in Southern Brazil, has 421,240 inhabitants and is one of the three with the highest Human Development Index in the country.

\section{SAMPLING PROCEDURES}

A multi-stage sampling method was used for sample selection, considering census tracts as the primary sample unit (PSU). Firstly, 420 census tracts of the city were ordered according to the average income of the household head. Then, they were grouped in deciles and 63 of them were systematically drawn (approximately six in each decile). Secondly, the field work team visited all census tracts in order to estimate the number of inhabited households in each one. After that, 18 households were drawn in each census tract, which is equivalent to 32 adults per PSU (considering the average of 1.78 adult per household), and 2,016 people in the whole city $(63 \times 32)$. With this sample size and considering a prevalence of exposure higher than $5 \%$, the study was able to detect odds ratios (OR) higher than 1.32 (risk) or lower than 0.76 (protection), adopting a $5 \%$ alpha and an $80 \%$ power.

\section{DATA COLLECTION}

The interviews were carried out between September 2009 and January 2010. All the selected households were visited at least four times in order to contact the residents (in all cases at least one visit was at night and another on the weekend). All residents were invited to participate voluntarily in the study, except individuals who did not have physical or psychological conditions to answer the questionnaire. Home visits included the administration 
of a face-to-face questionnaire, which was intensively tested in a pilot study conducted prior to the field work with 99 adults living in two census tracts, who were not included in the sample. A short version of the questionnaire (10 questions) was applied as data quality control. Therefore, about $15 \%(n=248)$ of the interviewees were contacted by telephone. Kappa values varied between 0.6 and 0.9 .

\section{OUTCOMES}

Analysis was carried out on the contextual factors associated with co-occurrence of four risk behaviors for chronic diseases and each risk behavior independently. Risk behaviors included tobacco smoking, abusive alcohol consumption, poor eating habits, and physical inactivity. Categories for smoking were nonsmoker, former smoker, or current smoker. For the purposes of the analysis, the "nonsmoker" and "former smoker" categories were grouped together and considered as free from risk to health. Problematic alcohol use was measured using the Alcohol Use Disorder Identification Test (AUDIT) ${ }^{14}$, which was validated in various countries and presented good levels of sensitivity (87.8\%) and specificity $(81 \%)^{15}$ for the detection of problematic alcohol use. In this study, this variable was defined by an AUDIT score above 7 .

Physical activities and eating habits were assessed according to the questionnaire used in the Surveillance of Risk Factors and Protection for Chronic Diseases Through Telephone Inquiries (VIGITEL), Brazil ${ }^{16,17}$. Adults were considered as physically inactive if they practiced physical activity during leisure time in less than once a week in the three months preceding the interview ${ }^{16}$. People who reported consuming fruits and vegetables less than five days a week were considered as having poor eating habits ${ }^{17}$.

\section{NEIGHBORHOOD EXPOSURE}

The mean of schooling years of the household head in each census tract was used as a contextual variable. After being collected as a discrete variable, information was divided into three categories: 0 to 8 years of study, 9 to 11 years, and 12 or more years. Data were gathered from the 2000 Brazilian census.

\section{INDIVIDUAL COVARIATES}

The analyzed individual covariates were: gender, age in completed years (20 to 29, 30 to 39,40 to 49 , and 50 to 59), equalized household income divided into tertiles, successfully completed school years ( 0 to 4, 5 to 8,9 to 11 , and $\geq 12$ ), and self-reported skin color (white or light- or dark-skinned black). 


\section{STATISTICAL ANALYSIS}

An estimate was carried out of the prevalence and respective $95 \%$ confidence interval of the co-occurrence of risk behaviors and of each risk factor independently. Multilevel logistic regression was applied to test the association between each risk factor and area-level education. The multilevel polytomous logistic regression was also run, using the multinomial logit model, to investigate the association between co-occurrence of risk factors $(0,1,2$, $3 / 4$ risk factors) and contextual variable. OR and respective $95 \%$ confidence interval were reported. We also estimated the proportion of total variance of each outcome, which is due to differences between the groups. The variance partition coefficient (VPC) was defined as level 2 variance/level 2 variance $+\left(\pi^{\wedge} 2 / 3\right)$. It provides a total variance estimation in outcomes that can be attributed to differences between the neighborhoods. Level of significance was defined at $p<0.05$. In both analyzes, the variables were gradually included in the models. The multilevel model added two levels of analysis: level-area schooling and individual characteristics. After the unadjusted model (crude analysis), age, gender and race/skin color were included (Model 1). Finally, in the full model, we included individual-level education and equalized household income (Model 2). The multilevel analysis used the fixed effects model and random intersection for estimation of the association between outcomes and explanatory variables of the first and second levels of the analysis. We calculated the Akaike information criterion as a measure of fit goodness. All analyses were carried out in Stata 13 program, taking the weighted sample into account.

\section{ETHICAL ASPECTS}

This research was approved by the Ethics Committee of Research with Human Beings of Universidade Federal de Santa Catarina. All participants signed a free informed consent form (process number 351/08).

\section{RESULTS}

1,720 individuals were interviewed (response rate of $85.3 \%$ ). Table 1 shows the main characteristics of the studied population. About $55.5 \%$ were women, $85.7 \%$ reported being white, and $44.4 \%$ were 40 years or older. Most interviewees declared having more than eight years of education (77.3\%). Unhealthy eating was the most common risk behavior among the population ( $81.2 \%)$, followed by physical inactivity $(53.1 \%)$. Around one among five people (19.2\%) were current smokers, and $18.5 \%$ reported problematic alcohol use.

The prevalence of smoking, unhealthy eating and physical inactivity was higher among individuals with lower level of education and lower household income. In addition, neighborhoods with lower educational levels showed higher prevalence of unhealthy eating and 
Table 1. Sample distribution and prevalence of smoking, problematic use of alcohol, unhealthy eating, and physical inactivity according to individual and contextual characteristics, Florianópolis, Brazil, 2009-2010.

\begin{tabular}{|c|c|c|c|c|c|}
\hline $\begin{array}{l}\text { Variables } \\
(n=1,720)\end{array}$ & $\begin{array}{l}\text { Sample } \\
\text { n (\%) }\end{array}$ & $\begin{array}{l}\text { Smoking } \\
\%(95 \% \mathrm{Cl})\end{array}$ & $\begin{array}{c}\text { Problematic use } \\
\text { of alcohol } \\
\%(95 \% \mathrm{Cl})\end{array}$ & $\begin{array}{l}\text { Unhealthy eating } \\
\qquad \%(95 \% \mathrm{Cl})\end{array}$ & $\begin{array}{l}\text { Physical } \\
\text { inactivity } \\
\%(95 \% \mathrm{Cl})\end{array}$ \\
\hline \multicolumn{6}{|l|}{ Age (years) } \\
\hline $20-29$ & $540(32.7)$ & $18.0(14.6-21.4)$ & $26.4(20.3-32.4)$ & $89.2(86.2-92.3)$ & $45.9(40.5-51.2)$ \\
\hline $30-39$ & $392(22.9)$ & $15.7(11.7-19.8)$ & $15.6(11.3-19.9)$ & $82.5(78.0-87.0)$ & $56.4(50.7-62.0)$ \\
\hline $40-49$ & $438(25.0)$ & $18.6(15.0-22.2)$ & $15.5(11.9-19.1)$ & $75.1(70.1-80.0)$ & $55.5(49.6-61.4)$ \\
\hline $50-59$ & $350(19.4)$ & $26.1(21.8-30.4)$ & $12.6(8.8-16.3)$ & $73.9(68.3-79.6)$ & $58.3(50.4-66.1)$ \\
\hline \multicolumn{6}{|l|}{ Gender } \\
\hline Male & $761(44.5)$ & $21.3(18.2-24.4)$ & $29.6(25.3-33.9)$ & $86.5(83.2-89.9)$ & $46.3(40.7-51.8)$ \\
\hline Female & 959 (55.5) & $17.5(14.8-20.2)$ & $9.6(6.9-12.3)$ & $76.9(73.6-80.1)$ & $58.5(53.8-63.3)$ \\
\hline \multicolumn{6}{|l|}{ Skin color } \\
\hline White & $1,444(85.7)$ & $18.4(16.2-20.5)$ & $17.3(14.8-19.8)$ & $80.6(77.7-83.6)$ & $51.9(43.1-52.8)$ \\
\hline $\begin{array}{l}\text { Lighter } \\
\text { skinned } \\
\text { Black }\end{array}$ & $147(9.1)$ & $24.9(17.6-32.2)$ & $28.4(19.6-37.2)$ & $87.0(80.8$ - 93.2) & $55.9(47.7-64.2)$ \\
\hline $\begin{array}{l}\text { Dark } \\
\text { skinned } \\
\text { Black }\end{array}$ & $87(5.2)$ & $20.8(12.6-29.1)$ & $19.6(9.2-30.1)$ & $83.2(73.9-92.4)$ & $68.3(60.2-76.4)$ \\
\hline
\end{tabular}

Individual educational level (years of successful studies)

\begin{tabular}{l|l|l|l|l|l|}
\hline$\leq 4$ & $158(8.7)$ & $27.0(19.2-34.8)$ & $14.3(7.0-21.6)$ & $88.1(82.4-93.8)$ & $82.6(75.8-89.3)$ \\
\hline $5-8$ & $253(14.0)$ & $25.9(17.9-33.9)$ & $14.6(8.7-20.5)$ & $87.6(83.4-91.8)$ & $68.8(62.0-75.7)$ \\
\hline $9-11$ & $568(33.4)$ & $21.4(17.7-25.2)$ & $20.5(15.8-25.1)$ & $84.9(82.0-87.7)$ & $57.3(52.1-62.5)$ \\
\hline$\geq 12$ & $737(43.9)$ & $13.9(11.4-16.5)$ & $19.2(15.3-23.1)$ & $74.9(70.1-79.8)$ & $38.7(35.1-32.4)$ \\
\hline
\end{tabular}

Equalized household income (tertile)

\begin{tabular}{l|c|c|c|c|c|}
\hline Poorest & $574(33.1)$ & $23.6(20.3-27.2)$ & $16.8(13.5-20.8)$ & $86.5(83.2-89.2)$ & $65.3(59.0-71.2)$ \\
\hline Intermediate & $573(32.6)$ & $21.8(17.7-26.5)$ & $20.2(15.8-25.4)$ & $84.3(81.0-87.1)$ & $53.9(49.2-58.6)$ \\
\hline Richest & $572(34.3)$ & $12.6(9.9-16.1)$ & $18.6(14.8-23.2)$ & $73.2(67.6-78.1)$ & $40.7(36.1-45.5)$ \\
\hline
\end{tabular}

Area-level education (years of successful studies; 63 census tracts)

\begin{tabular}{l|c|c|c|c|c|}
\hline$\geq 12$ & $427(26.9)$ & $18.6(14.6-23.5)$ & $16.3(12.1-21.7)$ & $71.4(64.5-77.4)$ & $43.4(39.0-48.0)$ \\
\hline $9-11$ & $741(42.2)$ & $17.0(14.4-20.1)$ & $21.2(16.1-27.6)$ & $81.5(77.8-84.7)$ & $50.2(44.3-56.2)$ \\
\hline$\leq 8$ & $552(30.9)$ & $22.7(19.2-26.7)$ & $16.7(13.0-21.6)$ & $89.3(86.0-91.9)$ & $65.6(57.8-72.5)$ \\
\hline $\begin{array}{l}\text { Total } \\
\text { Cl: confidence interval. }\end{array}$ & $1720(100.0)$ & $19.2(17.1-21.3)$ & $18.5(15.5-21.4)$ & $81.2(78.3-84.1)$ & $53.1(48.8-57.4)$ \\
\hline
\end{tabular}


physical inactivity. $3.4 \%$ of adults presented the four risk behaviors simultaneously, and $8.2 \%$ reported none of the unhealthy behaviors. The highest prevalence observed was unhealthy diet plus physical inactivity (30.6\%). Other prevalence combinations of health risk behaviors are described in Table 2.

After analyzing the risk factors independently, in the empty model, we observed that the between-group variance corresponded to $7.79,7.11$ and $6.84 \%$ for physical inactivity, problematic alcohol use, and unhealthy eating habits, respectively (Table 3 ). The value was particularly low for smoking $(1.08 \%)$. Area-level education explained a significant proportion of the variance when analyzing unhealthy eating habits and physical inactivity, but not for problematic alcohol use. In the latter, we observed that individual demographic characteristics explained almost half of the variance.

Table 4 also shows the results of logistic regression analysis. In the fully adjusted model, residents of low education neighborhoods showed a 2.40 times higher chance of unhealthy eating and 1.78 times higher chance of physical inactivity. Smoking and problematic alcohol use were not associated with area-level education.

Table 2. Prevalence of combinations of health risk behaviors in the adult population, Florianópolis, Brazil, 2009-2010.

\begin{tabular}{|c|c|c|c|c|c|}
\hline Risk factors & Smoking & Drinking & Unhealthy diet & $\begin{array}{l}\text { Physical } \\
\text { inactivity }\end{array}$ & Prevalence $(95 \% \mathrm{Cl})$ \\
\hline 0 & - & - & - & - & $8.2(6.9-9.5)$ \\
\hline \multirow[t]{4}{*}{1} & - & - & - & + & $1.3(0.8-1.8)$ \\
\hline & - & - & + & - & $1.2(0.7-1.7)$ \\
\hline & - & + & - & - & $24.0(22.0-26.0)$ \\
\hline & + & - & - & - & $5.7(4.6-6.8)$ \\
\hline \multirow[t]{6}{*}{2} & + & + & - & - & $30.6(28.4-32.8)$ \\
\hline & + & - & + & - & $0.5(0.1-0.7)$ \\
\hline & + & - & - & + & $6.2(5.1-7.3)$ \\
\hline & - & + & + & - & $1.3(0.8-1.8)$ \\
\hline & - & + & - & + & $3.2(2.3-4.0)$ \\
\hline & - & - & + & + & $0.2(0.0-0.4)$ \\
\hline \multirow[t]{4}{*}{3} & + & + & + & - & $4.0(3.0-4.9)$ \\
\hline & + & + & - & + & $7.2(5.9-8.4)$ \\
\hline & + & - & + & + & $0.4(0.1-0.6)$ \\
\hline & - & + & + & + & $2.6(1.9-3.3)$ \\
\hline 4 & + & + & + & + & $3.4(2.6-4.3)$ \\
\hline
\end{tabular}


The likelihood of individuals having two or three/four risk factors simultaneously was higher among residents of low education neighborhoods (Table 3). In the crude analysis, the odds of adults having three/four risk factors simultaneously was 5.90 times higher in the residents of the least educated neighborhoods when compared to the reference group. The association remained statistically significant $(\mathrm{OR}=2.61 ; 95 \% \mathrm{CI} 1.22-5.62)$ even after

Table 3. Association between area-level education and smoking, problematic use of alcohol, unhealthy diet and physical inactivity, and variance estimates from multilevel models, Florianópolis, Brazil, 2009-2010.

\begin{tabular}{|c|c|c|c|c|c|c|}
\hline \multirow{2}{*}{$\begin{array}{l}\text { Area-level } \\
\text { education } \\
\text { (mean years } \\
\text { of schooling) }\end{array}$} & \multicolumn{3}{|c|}{ Logistic regression } & \multicolumn{3}{|c|}{ Variance estimates } \\
\hline & $\begin{array}{l}\text { Crude model OR } \\
\qquad(95 \% \mathrm{Cl})\end{array}$ & $\begin{array}{l}\text { Model } 1 \text { OR } \\
(95 \% \mathrm{Cl})\end{array}$ & $\begin{array}{l}\text { Model } 2 \text { OR } \\
(95 \% \mathrm{Cl})\end{array}$ & $\begin{array}{c}\text { VPC (\%) } \\
\text { Empty } \\
\text { model }\end{array}$ & $\begin{array}{l}\text { VPC } \\
(\%)^{*}\end{array}$ & $\begin{array}{l}\text { VPC } \\
(\%)^{* *}\end{array}$ \\
\hline \multicolumn{7}{|l|}{ Smoking } \\
\hline$\geq 12$ & Reference & Reference & Reference & \multirow{4}{*}{1.08} & \multirow{4}{*}{0.54} & \multirow{4}{*}{0.00} \\
\hline $9-11$ & $0.89(0.65-1.23)$ & $0.89(0.65-1.22)$ & $0.66(0.46-0.92)$ & & & \\
\hline$\leq 8$ & $1.22(0.86-1.73)$ & $1.18(0.83-1.69)$ & $0.70(0.47-1.03)$ & & & \\
\hline AIC & $11,837.7$ & $11,366.1$ & $10,915.7$ & & & \\
\hline \multicolumn{7}{|c|}{ Problematic use of alcohol } \\
\hline$\geq 12$ & Reference & Reference & Reference & \multirow{4}{*}{7.11} & \multirow{4}{*}{6.61} & \multirow{4}{*}{3.80} \\
\hline $9-11$ & $1.25(0.80-1.96)$ & $1.08(0.69-1.68)$ & $1.18(0.73-1.90)$ & & & \\
\hline$\leq 8$ & $0.97(0.63-1.47)$ & $0.86(0.56-1.33)$ & $0.97(0.61-1.55)$ & & & \\
\hline AIC & $11,385.2$ & $10,149.7$ & $9,896.7$ & & & \\
\hline \multicolumn{7}{|c|}{ Unhealthy eating } \\
\hline$\geq 12$ & Reference & Reference & Reference & \multirow{4}{*}{6.84} & \multirow{4}{*}{1.73} & \multirow{4}{*}{0.84} \\
\hline $9-11$ & $1.71(1.22-2.41)$ & $1.58(1.09-2.29)$ & $1.34(0.95-1.89)$ & & & \\
\hline$\leq 8$ & $3.25(2.17-4.87)$ & $3.17(2.06-4.88)$ & $2.40(1.58-3.66)$ & & & \\
\hline AIC & $11,293.3$ & $10,469.2$ & $10,095.1$ & & & \\
\hline \multicolumn{7}{|c|}{ Physical inactivity } \\
\hline$\geq 12$ & Reference & Reference & Reference & \multirow{4}{*}{7.79} & \multirow{4}{*}{4.58} & \multirow{4}{*}{5.19} \\
\hline $9-11$ & $1.29(0.96-1.74)$ & $1.34(0.98-1.84)$ & $1.07(0.76-1.51)$ & & & \\
\hline$\leq 8$ & $2.41(1.65-3.50)$ & $2.47(1.67-3.64)$ & $1.78(1.19-2.67)$ & & & \\
\hline AIC & $16,210.0$ & $15,542.4$ & $14,674.5$ & & & \\
\hline
\end{tabular}

AIC: Akaike's information criterion; OR: odds ratio; Cl: confidence interval; VPC: variance partition coefficient; Model 1: adjusted by age, skin color and gender; Model 2: model 1 + individual-level education and equalized household income; *adjusted by area-level education; **adjusted by area-level education, age, gender, skin color, individual-level education, and equalized household income. 
adjustment for all individual variables. We tested for but did not find any statistical crosslevel interaction between the outcomes and sex, educational level.

\section{DISCUSSION}

The association between co-occurrence of behavior-related risk factors and area-level education can be highlighted as the major find of this study. Regardless of personal socioeconomic and demographic characteristics, individuals residing in low education neighborhoods had higher chances of reporting two or more risk factors simultaneously. We also found that the prevalence of unhealthy eating and physical inactivity was higher among neighborhoods with lower educational level. We observed a significant between-group variance for all risk factors, but smoking. Finally, area-level education explained a significant proportion of this variance when analyzing unhealthy eating habits and physical inactivity.

Regarding the higher co-occurrence of risk factors in disadvantaged neighborhoods, results reported in this Brazilian study corroborate the findings of two other researches

Table 4. Association between cumulative risk factors and area-level education, Florianópolis, Brazil, 2009-2010.

\begin{tabular}{|c|c|c|c|c|c|}
\hline \multirow{2}{*}{$\begin{array}{l}\text { Number of risk } \\
\text { factors }\end{array}$} & \multicolumn{3}{|c|}{ Area-level education (mean years of schooling) } & \multirow[b]{2}{*}{ VPC (\%) } & \multirow[b]{2}{*}{ AIC } \\
\hline & $\begin{array}{c}\geq 12 \text { years OR } \\
(95 \% \mathrm{Cl})\end{array}$ & $\begin{array}{c}9-11 \text { years OR } \\
(95 \% \mathrm{Cl})\end{array}$ & $\begin{array}{c}\leq 8 \text { years OR } \\
(95 \% \mathrm{Cl})\end{array}$ & & \\
\hline \multicolumn{6}{|l|}{ Crude analysis } \\
\hline 1 risk factor & Reference & $1.40(0.81-2.40)$ & $2.69(1.32-5.46)$ & \multirow{3}{*}{14.2} & \multirow{3}{*}{$29,237.1$} \\
\hline 2 risk factors & Reference & $1.86(1.06-3.24)$ & $5.48(2.83-10.6)$ & & \\
\hline 3 to 4 risk factors & Reference & $1.87(1.01-3.44)$ & $5.90(2.92-11.89)$ & & \\
\hline \multicolumn{6}{|l|}{ Model 1} \\
\hline 1 risk factor & Reference & $1.31(0.76-2.28)$ & $2.68(1.33-5.40)$ & \multirow{3}{*}{14.1} & \multirow{3}{*}{$27,959.6$} \\
\hline 2 risk factors & Reference & $1.75(0.99-3.10)$ & $5.53(2.88-10.62)$ & & \\
\hline 3 to 4 risk factors & Reference & $1.65(0.87-3.11)$ & $5.42(2.68-10.97)$ & & \\
\hline \multicolumn{6}{|l|}{ Model 2} \\
\hline 1 risk factor & Reference & $1.30(0.74-2.28)$ & $2.63(1.28-5.39)$ & \multirow{3}{*}{13.8} & \multirow{3}{*}{$26,741.2$} \\
\hline 2 risk factors & Reference & $1.43(0.82-2.48)$ & $4.03(2.14-7.60)$ & & \\
\hline 3 to 4 risk factors & Reference & $1.08(0.56-2.07)$ & $2.61(1.22-5.62)$ & & \\
\hline
\end{tabular}

AIC: Akaike's information criterion; OR: odds ratio; Cl: confidence interval; VPC: variance partition coefficient; Model 1: adjusted by age, skin color and gender; Model 2: model $1+$ individual-level education and equalized household income. 
carried out in developed countries. After analyzing data from the Finnish population, Halonen et al. ${ }^{11}$ reported higher likelihood of co-occurrence of three behavior-related risk factors with increasing neighborhood deprivation. Similarly, Lakshman et al. ${ }^{18}$ analyzed data of 26,290 English adults on physical activity, smoking, fruit consumption, and alcohol intake and found an inverse association between the co-occurrence of these risk factors with neighborhood disadvantage. Other studies analyzing the association between neighborhood socioeconomic status and health-related behaviors reported individual results for each risk factor.

Different lines of reasoning have been raised to explain the association between neighborhood socioeconomic status and health behaviors. One of them is related to better physical structure found in more affluent neighborhoods. Studies have reported that accessibility of facilities and opportunities for physical activity in the neighborhoods are both associated with a higher level of physical activity ${ }^{19}$, and physical activity facilities are less often found in the most disadvantaged neighborhoods ${ }^{20,21}$. According to van Lenthe et al. ${ }^{22}$, there is a larger amount of police attention required to perform sports activities in underprivileged neighborhoods, besides a poorer general physical design, factors that help to explain socioeconomic inequalities in the physical activity observed among neighborhoods. Higher demand for domestic work may decrease the opportunities of women who live in poor neighborhoods at engaging in physical activities during their leisure time.

A similar pattern is observed when the offer of healthy food is analyzed. A review study carried out by Larson et al. ${ }^{23}$ analyzed 54 researches completed in the US between 1985 and 2008 and reported that people living in the poorest neighborhoods access less supermarkets and healthy food. Furthermore, there is higher availability of fast-food restaurants and energy-dense foods in disadvantaged neighborhoods. Similar results were found in Brazil, Europe and Oceania ${ }^{24,25}$. According to a systematic review conducted by Pitt et al. ${ }^{26}$, food availability, quality and food store characteristics greatly influence in-store purchases. Therefore, the lower the availability of healthy foods, the less likely the population to consume healthy food.

Additionally to the built environment factors, a context of higher levels of violence and eventually lack of social capital in more disadvantaged neighborhoods may facilitate the assumption of unhealthy behaviors, such as smoking and drinking, which makes other healthy behaviors more difficult, such as the practice of physical activities. This body of evidence highlights that it is harder to be healthy when living in underprivileged neighborhoods, a situation that claims for strong public policy action.

Area-level education was highly associated with the co-occurrence of multiple risk factors. Communities with higher level of education may be more capable of demanding - and receiving - better public and private facilities from the government and private sector. Another point that must be highlighted is the possible spillover effect of education. Higher educated people are more likely to receive, interpret, and correctly implement health orientations that are beneficial to them. In communities with higher proportion of highly 
educated people, this knowledge is easier, and its consequences spread and influence other residents in the community.

This study has some limitations. Firstly, it is cross-sectional, so it is not possible to declare the association between outcome and associated factors as causal. Second, there may be an information bias. People may tend to report patterns of social behaviors, such as smoking, alcohol use, physical activity and eating habits, which are more socially accepted. In order to avoid such problem, we used validated questionnaires and carried out interviews only in the participant and interviewer's presence. In addition, the field work team was trained not to judge or give any opinion about the participants' answers. Contextual educational data came from the 2000 Brazilian census, and information of outcomes were collected in 2009/2010. The 2010 National Census, unfortunately, did not collect data on the study years. This is another study limitation, notwithstanding the fact that there is a latency time between neighborhood exposures and health effects ${ }^{27}$. The association between outcomes and exposures may be different for men and women, but our study did not explore this dimension due to lack of sampling power. Finally, there may be additional individual-level confounders not considered in this study that could have weakened the observed associations.

As strengths of this study we can mention the high obtained response rate - equally distributed among the income deciles of the census tracts - , the use of validated questionnaires, and the similar sample sociodemographic composition when compared with the populational estimative made by the Instituto Brasileiro de Geografia e Estatística (IBGE) for the city.

\section{CONCLUSIONS}

Residing in low education neighborhoods increases the chances of reporting two or more risk factors simultaneously. Prevalence of unhealthy eating and physical inactivity is higher among lower education neighborhoods. There is a significant between-group variance for all risk factors, except smoking. Chronic diseases are a major problem all over the world, mainly outside the rich countries. Results reinforce the urgent need to broaden the scope of public policies. To be more effective, besides individual characteristics, they should also consider the environment in which people live.

\section{ACKNOWLEDGMENTS}

This work was supported by the Brazilian National Council for Scientific and Technological Development (485327 / 2007-4). AFB received a post-doctorate scholarship from Coordenação de Aperfeiçoamento de Pessoal de Nível Superior - CAPES (3111-13-0) and grants for research productivity (Conselho Nacional de Desenvolvimento Científico e Tecnológico - CNPq). 


\section{REFERENCES}

1. World Health Organization. Global health risks: mortality and burden of disease attributable to selected major risks. Geneva: World Health Organization; 2009.

2. World Health Organization. Preventing chronic diseases: a vital investment. Geneva: World Health Organization; 2009.

3. Fornari C, Donfrancesco C, Riva MA, Palmieri L, Panico S, Vanuzzo D, et al. Social status and cardiovascular disease: a Mediterranean case. Results from the Italian Progetto CUORE cohort study. BMC Public Health 2010; 10: 574. https: / / doi.org/10.1186/1471-2458-10-574

4. Hosseinpoor AR, Parker LA, Tursan d'Espaignet E, Chatterji S. Socioeconomic inequality in smoking in low-income and middle-income countries: results from the World Health Survey. PLoS One 2012; 7(8): e42843. https: / / doi.org/10.1371/journal.pone.0042843

5. Hill TD, Angel RJ. Neighborhood disorder, psychological distress, and heavy drinking. Soc Sci Med 2005; 61(5): 965-75. https:// doi.org/10.1016/j. socscimed.2004.12.027

6. Pearce J, Blakely T, Witten K, Bartie P. Neighborhood deprivation and access to fast-food retailing: a national study. Am J Prev Med 2007; 32(5): 375-82. https: / / doi. org/10.1016/j.amepre.2007.01.009

7. Turrell G, Haynes M, Burton NW, Giles-Corti B, Oldenburg B, Wilson LA, et al. Neighborhood disadvantage and physical activity: baseline results from the HABITAT multilevel longitudinal study. Ann Epidemiol 2010; 20(3): 171-81. https:// doi. org/10.1016/j.annepidem.2009.11.004

8. Cohen SS, Sonderman JS, Mumma MT, Signorello $\mathrm{LB}$, Blot WJ. Individual and neighborhood-level socioeconomic characteristics in relation to smoking prevalence among black and white adults in the Southeastern United States: a cross-sectional study. BMC Public Health 2011; 11: 877. https://doi. org/10.1186/1471-2458-11-877

9. Macintyre S, Ellaway A. Neighborhoods and health: an overview. New York: Oxford; 2003.

10. Yusuf S, Hawken S, Ounpuu S, Dans T, Avezum A, Lanas F, et al. Effect of potentially modifiable risk factors associated with myocardial infarction in 52 countries (the INTERHEART study): case-control study. Lancet 2004; 364(9438): 937-952. https:// doi. org/10.1016/S0140-6736(04)17018-9

11. Halonen JI, Kivimäki M, Pentti J, et al. Quantifying neighbourhood socioeconomic effects in clustering of behaviour-related risk factors: a multilevel analysis. PLoS One 2012; 7(3): e32937. https: / / doi.org/10.1371/ journal.pone.0032937
12. Poortinga W. The prevalence and clustering of four major lifestyle risk factors in an English adult population. Prev Med 2007; 44(2): 124-8. https: / / doi. org/10.1016/j.ypmed.2006.10.006

13. Macintyre S, Maciver S, Sooman A. Area, class and health: should we be focusing on places or people? J Soc Policy 1993; 22(2): 213-34. https:// doi.org/10.1017/ S0047279400019310

14. Babor T, Higgins-Biddle J, Saunders J, Monteiro M. AUDIT, the Alcohol Use Disorders Identification Test: guidelines for use in primary care. Geneva: World Health Organization; 2001.

15. Lima CT, Freire AC, Silva AP, Teixeira RM, Farrell M, Prince M. Concurrent and construct validity of the audit in an urban Brazilian sample. Alcohol Alcohol 2005; 40(6): 584-9. https://doi.org/10.1093/alcalc/ agh202

16. Florindo AA, Hallal PC, Moura EC, Malta DC. Practice of physical activities and associated factors in adults, Brazil, 2006. Rev Saúde Pública 2009; 43(Suppl. 2): S65-S73. https://doi.org/10.1590/ s0034-89102009000900009

17. Jaime PC, Figueiredo IC, Moura EC, Malta DC. Factors associated with fruit and vegetable consumption in Brazil, 2006. Rev Saúde Pública 2009; 43(Suppl. 2): S57S64. https: / / doi.org/10.1590/s0034-89102009000900008

18. Lakshman R, McConville A, How S, Flowers J, Wareham N, Cosford P. Association between area-level socioeconomic deprivation and cluster of behavioural risk factors: cross-sectional, population-based study. J Public Health 2011; 33(2): 234-45. https:/ / doi. org/10.1093/pubmed/fdq072

19. Humpel N, Owen N, Leslie E. Environmental factors associated with adults' participation in physical activity: a review. Am J Prev Med 2002; 22(3): 188-99.

20. Estabrooks PA, Lee RE, Gyurcsik NC. Resources for physical activity participation: does availability and accessibility differ by neighborhood socioeconomic status? Ann Behav Med 2003; 25(2): 100-4. https:// doi.org/10.1207/S15324796ABM2502_05

21. Gordon-Larsen P, Nelson MC, Page P, Popkin BM. Inequality in the built environment underlies key health disparities in physical activity and obesity. Pediatrics 2006; 117(2): 417-24. https: / / doi.org/10.1542/peds.2005-0058 22. van Lenthe FJ, BrugJ, Mackenbach JP. Neighbourhood inequalities in physical inactivity: the role of neighbourhood attractiveness, proximity to local facilities and safety in the Netherlands. Soc Sci Med 2005; 60(4): 763-75. https:// doi.org/10.1016/j. socscimed.2004.06.013 
23. Larson NI, Story MT, Nelson MC. Neighborhood environments: disparities in access to healthy foods in the U.S. Am J Prev Med 2009; 36(1): 74-81. https: / / doi.org/10.1016/j.amepre.2008.09.025

24. Duran AC, Diez Roux AV, Latorre MR, Jaime PC. Neighborhood socioeconomic characteristics and differences in the availability of healthy food stores and restaurants in Sao Paulo, Brazil. Health Place 2013; 23: 39-47. https:// doi.org/10.1016/j. healthplace.2013.05.001

25. Hilmers A, Hilmers DC, Dave J. Neighborhood disparities in access to healthy foods and their effects on environmental justice. Am J Public Health 2012; 102(9): 1644-54. https://dx.doi. org/10.2105\%2FAJPH.2012.300865

26. Pitt E, Gallegos D, Comans T, Cameron C, Thornton L. Exploring the influence of local food environments on food behaviours: a systematic review of qualitative literature. Public Health Nutr 2017; 20(13): 2393-405. https: / doi.org/10.1017/S1368980017001069

27. Höfelmann DA, Antunes JLF, Silva DAS, Peres MA. Is income area level associated with blood pressure in adults regardless of individual-level characteristics? A multilevel approach. Health \& Place 2012; 18(5): 971-7. https: / / doi.org/10.1016/j.healthplace.2012.06.010

Received on: 07/30/2018

Revised on: 11/02/2018

Accepted on: 11/09/2018

Authors' collaboration: AFB and ACB participated on the study concept and design, data analysis and interpretation, and drafting the manuscript. SVS was part of the study concept and design and critical revision of the manuscript for important intellectual content. 